\title{
Promoting the Well-Being of All Children: An Introduction to a Special Issue Featuring the Doris Duke Fellowship
}

\author{
Kathryn Maguire-Jack ${ }^{1} \cdot$ Paul Lanier $^{2}$ (D)
}

Published online: 27 December 2016

(C) Springer Science+Business Media New York 2016

\section{Introduction}

The promotion of child well-being means taking proactive efforts to secure the right of all children to engage with the world in child-appropriate ways and to maximize child health at all stages of development (Raghavan and Alexandrova, 2015). Healthy child development is uniquely important to public health because, put simply, childhood does not get a "do-over." Despite the amazing resilience of the human body and mind, critical aspects of human development occur only during childhood. However, children have little control over their environment, so adults must act as agents to shape children's worlds to optimize well-being.

Fortunately, many children live in homes and communities that promote well-being and require limited formal intervention. The Centers for Disease Control and Prevention's (2014) concept of "safe, stable, nurturing relationships and environments" exists, almost by default, for a large portion of children who were endowed at conception with a prepared and supported birth family. Other children are not as fortunate. Their daily experience is a world of disorder, trauma, and inadequate concrete support. However, child well-being is not distributed randomly in our society, and many children enter into relationships with their parents and social environments that do not promote their well-being.

Paul Lanier

planier@email.unc.edu

1 College of Social Work, The Ohio State University, Columbus, USA

2 School of Social Work, UNC Chapel Hill, 325 Pittsboro Street, Chapel Hill, NC 27599-3550, USA
For most children, the child's relationship with his or her caregiver is arguably the most powerful predictor of well-being. As children age, the environment (e.g., peers, schools) takes a greater share of influence, but the importance of the adult caregiver is a persistent force. All other factors equal, when the child-caregiver relationship is healthy, children flourish. Unfortunately, caregiving behavior can shift in a negative direction due to competing demands and pervasive risk factors, and many children suffer abuse and neglect. Decades of research have documented the damage that maltreatment can do to the developing child. Therefore, the prevention of maltreatment must be a cornerstone of any broad efforts to promote child well-being (Lanier et al., 2015a).

Child maltreatment is not a rare occurrence. Each year, the US Children's Bureau documents the scope of the problem by compiling data from state and county child protective services (CPS) agencies. In federal Fiscal Year 2014, nearly 3.2 million children were the subject of a formal report of maltreatment made to authorities (US Department of Health and Human Services [US DHHS], 2016). This number represents a sizeable proportion of the 73.6 million children in the US population (Federal Interagency Forum on Child and Family Statistics, 2016). However, these annual numbers mask the cumulative number of children maltreated during their entire childhood. A recent study using synthetic cohort life tables reported that before the age of 18 years, 1 in 8 children will experience maltreatment confirmed by a CPS agency-a rate 14 times higher than the annual maltreatment prevalence rate alone (Wildeman et al., 2014). However, trends over the long- and shortterm indicate that overall annual rates of maltreatment are declining, with some scholars suggesting these rates are even reaching historical lows (Finkelhor et al., 2015). The positive gains are quite noticeable for physical and sexual 
abuse, but rates of neglect remain stable. These trends suggest progress in our ability to address the problem of child abuse, but also highlight the persistent challenge of reducing neglect, a problem that suffers from less policy attention and public awareness (Finkelhor et al., 2015).

Combined with the scope of the problem, strong evidence indicates that exposure to maltreatment increases the risk for a host of negative outcomes, all of which have a substantial cost to society. One study estimated that the lifetime costs of maltreatment as $\$ 210,012$ per victim and $\$ 1,272,900$ per child death (Fang et al., 2012). Just new cases of maltreatment in a single year carry a cost burden of $\$ 124$ billion, with estimates ranging as high as \$585 billion (Fang et al., 2012). Although preventing maltreatment is a necessary goal, our efforts should not end there. Health is more than the absence of disease. The alternative to preventing maltreatment must be actively promoting well-being.

\section{Promotion of Child Well-Being is a Goal of Child Welfare Policy}

Passage of the Adoption and Safe Families Act (ASFA) of 1997 included sweeping changes in the public response to child maltreatment and directed child welfare agencies to emphasize children's health and safety as their primary goal. This policy goal was enforced by requiring states to comply with specific targets as a prerequisite for continuing to receive federal funds for child welfare. The five principles of the ASFA legislation were outlined as follows: (a) safety is the paramount concern that must guide all child welfare services; (b) foster care is temporary; (c) permanency planning efforts should begin as soon the child enters care; (d) the child welfare system must focus on results and accountability; and (e) innovative approaches are needed to achieve the goals of safety, permanency, and well-being.

Despite ASFA's statutory mandate that the formal child welfare system should emphasize child well-being, children entering the child welfare system often do not fare well. Almost one-quarter of substantiated victims of maltreatment enter foster care. In 2014, more than 400,000 children were in foster care. In that same year, about half of the children who exited foster care were reunited with a primary caregiver; across all children who exited foster care, the median time in care was 13 months (US DHHS, 2016). Perhaps the most tragic evidence of the systematic failure to promote the wellbeing of children in care has come from studies of youth who age out of the foster care system without a permanent home. A large longitudinal study followed foster youth from age 17 or 18 years into their early adulthood. Results from the recent follow-up at age 26years found that as compared with their peers, the group of former foster youth were "faring poorly" on a host of social, economic, and health outcomes (Courtney et al., 2011). Indeed, child welfare is a "wicked problem" that must be met with evidence-based practice and strategic policy solutions (Wicked Problems Institutes, 2014).

\section{Current Strategies to Prevent Maltreatment}

Certainly the best approach to promoting child well-being would be to prevent maltreatment from ever occurring. Many existing policies and programs have sufficient evidence to suggest they are effective in preventing maltreatment. These interventions are targeted at the individual level and not only include programs to improve parenting skills and parent-child attachment but also include policies that make it easier for parents to create safe, stable, and nurturing relationships with their children. Every day, families living in poverty face numerous challenging decisions regarding the well-being of their children. However, many families do not get the help they need, despite the availability of effective supportive interventions. For example, based on a nationally representative survey, about only $20 \%$ of low-income children in the United States received homevisiting services before the age of 3 years (Lanier et al., 2015b). Evidence-based early home-visiting has a strong and growing empirical base supporting its effectiveness in preventing maltreatment (as well as promoting a host of other positive maternal and child health outcomes), and yet these programs are far from universally available, even for the most vulnerable families. Home visiting is just one approach. Two recent reports have described a broad continuum of evidence-based preventive interventions available to support and educate parents, which are also effective in preventing maltreatment (Institute of Medicine and National Research Council, 2014; National Academies of Sciences, Engineering, and Medicine 2016).

Beyond programs that target individual families, broader public policies that might seem unrelated to child wellbeing can influence rates of child maltreatment (Klevens et al., 2015). Recent studies have found associations between maltreatment and public policies such as paid family leave (Klevens et al., 2016), access to health care and child care (Klevens et al., 2015), and an increased minimum wage (Raissian and Bullinger, 2016). The caregiver-child relationship develops in the context of the social environment, a landscape that can be shaped by public policy.

\section{A Public Health Approach with Transdisciplinary Research}

A vibrant, innovative system of research is required to expand our repertoire of evidence-based programs and policies that prevent maltreatment and promote optimal child 
well-being. Child maltreatment prevention is best conceptualized as a public health problem (Hammond, 2003) and similar to other forms of violence, this public health approach provides a framework for addressing maltreatment prevention. Maltreatment research must move through four iterative phases to detect the scope and nature of the problem, identify malleable risk and protective factors, design and test interventions, and then scale-up only those interventions determined to be the most effective. The collaborative efforts of researchers of different disciplinary backgrounds and orientations are needed to do this work and to bridge scientific communities that include epidemiologists, developmental specialists, services researchers, and implementation scientists. The Doris Duke Fellowship is one example of a strategy that holds promise for building this disciplinary bridge.

\section{Doris Duke Fellowship}

In recognition of the importance of enhancing child wellbeing, the Doris Duke Charitable Foundation (DDCF) has invested significant resources to train PhD-level researchers to increase the understanding of how to effectively prevent child abuse and neglect. Beginning in 2011, DDCF began funding up to 15 dissertation fellows per year under the Doris Duke Fellowships for the Promotion of Child WellBeing. The Fellowship is currently funding their seventh cohort of fellows, bringing the total number of fellows supported through the program to 105 . The Fellowship is multidisciplinary, engaging emerging scholars from a diverse set of disciplines, including social work, sociology, nursing, public policy, public health, pediatrics, psychology, education, child development, and anthropology. In addition to generous research support, the Fellowship requires its fellows to have academic and policy/practice mentors to ensure that the research is rigorous and, once completed, is translated into policy and/or practice. A key component of the Fellowship is the peer-learning network, which includes fellows from across cohorts working collaboratively on innovative projects, research studies, and publications. The commentary by Adedokun and Daro (2016) provides indepth information on the Fellowship.

The Doris Duke fellows work collaboratively in myriad ways to advance knowledge within the area of maltreatment prevention. In one such effort, a group of fellows authored an edited volume Advances in Child Abuse Prevention Knowledge: The Perspective of New Leadership (Daro et al., 2015). This book explores new research methods and frameworks for advancing innovative maltreatment prevention strategies and showcases the work of one group of new scholars entering the field of child abuse and neglect research.

\section{Overview of the Special Issue}

The articles presented in this special issue make important individual contributions to a variety of areas related to promoting optimal child well-being. Mirroring the cross-disciplinary nature of the Doris Duke Fellowship, the authors come from a variety of disciplines, including social work, child development, special education, and psychology. Although not an intentional design of the special issue, these articles share a thematic function and identify a gap in much of the current research: to illuminate important perspectives not typically reflected in the scientific literature. Much of the current literature focuses on maltreated children and their biological parents as well as professionals working within the CPS system. To the extent that research evidence influences public policy, inattention to other key perspectives is potentially detrimental to these populations. This special issue includes research on underrepresented populations such as external collaborators to child welfare and youth who aged out of foster care who are now parents. Additionally, four of the studies used methods that specifically examined individual perspectives (three used qualitative methods to understand respondents' experiences and one used a mixed-methods design) and one used person-centered quantitative methods. Finally, all five articles make specific advancements recommended by Doris Duke Fellows contributing chapters in Advances in Child Abuse Prevention Knowledge (Daro et al., 2015). The themes shared by both the chapter authors and the authors of articles in this special issue include the following:

- working across disciplines and service systems to implement evidence-based strategies as well as to innovate new strategies for prevention (Powell et al., 2015; Corr and Santos 2016);

- incorporating the perspective of foster parents to increase the pool of high-quality foster care placements (Dierkhising et al., 2015; Geiger et al., 2016);

- using latent class analysis to understand subpopulations (Van Scoyoc et al., 2015; Katz et al. 2016).

- examining the perspective of youth who are aging out of foster care as a critical opportunity to prevent the intergenerational transmission of maltreatment (Geiger et al., 2015; Schelbe and Geiger 2016); and

- considering maltreatment within the host of adversities that often co-occur during childhood (Van Scoyoc et al., 2015, 2016).

In the first article of this issue, Corr (Doris Duke fellow) and Santos discuss the need to understand the perspectives of two systems that often serve the same families. The authors examine the overlap between the child welfare system and early intervention system. Using interviews 
and surveys with service providers and agency leaders, the authors explore the need to overcome organizational barriers to collaboration toward achieving the goal of better serving the children and families receiving services in these overlapping systems.

The issue's second article by Geiger et al., all of whom are Doris Duke fellows, brings the voice of foster parents to the forefront. The authors used data obtained from a survey of more than 1000 foster parents to understand how interactions with child welfare systems affect foster parents' ability to provide care. The authors examine the areas of child welfare services in which foster parents believed the caseworkers were doing well and the areas for which foster parents had suggestions for improving relations between foster parents and caseworkers.

The third article, from Katz (Doris Duke fellow), Courtney (Doris Duke academic mentor), and Novotny, uses person-centered methods to explore how children's experiences of maltreatment before foster care relates to experiences of maltreatment that occurred while the children were in care. The authors identify particular subpopulations for which efforts should be targeted to prevent recurrence of maltreatment.

The fourth article is authored by Schelbe and Geiger, both Doris Duke fellows. Their article reports on a study using qualitative methods to explore the parenting experiences of young adults who had been in foster care as youth and aged out of the system. The authors use field notes of observation and transcribed interviews to understand the challenges facing this population as well as the strength and resilience within this group.

Last, Van Scoyoc (Doris Duke fellow), Harrison, and Fisher (Doris Duke academic mentor) use semistructured interviews with women receiving in-patient substance abuse treatment services following drug use during pregnancy. The authors incorporate the perspectives of this high-risk population as an essential opportunity for increasing prevention efforts in a non-stigmatizing way.

\section{Limits of Empirical Research to Policy Development}

In her commentary, Berliner (2016) identifies the limits of evidence in the process of evidence-based policy making. She cautions that findings from research studies are just one piece of information that informs the public and their elected leaders' decisions regarding policy development. Even the best evidence can be overpowered by the social construction of target populations and the assumptions about the nature of social problems. Policy makers bring their own stories and understandings of why maltreatment occurs and have preconceived ideas about the best way to prevent maltreatment. These preconceptions might exist because, in the end, public health and child well-being at the population level is just the collection of many individual experiences. As compared with the best randomized trial or large-scale epidemiological study, bringing the voices of families, children, and child welfare professionals to the forefront can be equally as powerful in helping to develop and support effective policy. The work compiled in this special issue collectively demonstrates the ways in which rigorous research can bring important individual perspectives and experiences into the open.

Acknowledgements We would like to thank Diane Wyant at University of North Carolina at Chapel Hill for her editorial assistance in preparing this manuscript. We would also like to thank Deb Daro at Chapin Hall for her comments on an earlier draft. Most importantly, this special issue would not have been possible without the generous support of numerous anonymous peer reviewers.

\section{Compliance with Ethical Standards}

Conflict of interest Paul Lanier declares that he has no conflict of interest. Kathryn Maguire-Jack declares that she has no conflict of interest.

Ethical approval This article does not contain any studies with human participants performed by any of the authors.

\section{References}

Adedokun, L., \& Daro, D. (2016). The research the policy pipeline: The role of training emerging scholars. Child and Adolescent Social Work Journal. doi:10.1007/s10560-016-0477-x.

Adoption and Safe Families Act of 1997, Title 42, USC. § 629.

Berliner, L. (2016). A commentary on evidence-based policy to promote child well-being. Child and Adolescent Social Work Journal. doi:10.1007/s10560-016-0481-1.

Centers for Disease Control and Prevention. (2014). Essentials for childhood: Steps to create safe, stable, nurturing relationships and environments. Retrieved from https://goo.gl/zZ4tME.

Corr, \& Santos. (2016). "Not in the same sandbox": Cross-systems collaborations between early intervention and child welfare systems. Child and Adolescent Social Work Journal. doi:10.1007/ s10560-016-0470-4.

Courtney, M., Dworsky, A., Brown, A., Cary, C., Love, K., \& Vorhies, V. (2011). Midwest evaluation of the adult functioning of former foster youth: Outcomes at age 26. Chicago, IL: Chapin Hall at the University of Chicago.

Daro, D., Cohn Donnelly, A., Huang, L. A., \& Powell, B. (Eds.) (2015). Advances in child abuse prevention knowledge: The perspective of new leadership. Geneva: Springer International.

Dierkhising, C., Geiger, J., Hurst, T., Panlilio, C., \& Schelbe, L. (2015). Preventing adolescent maltreatment: a focus on child welfare, juvenile justice, and sexual exploitation. In D. Daro, A. Cohn Donnelly, L. A. Huang \& B. Powell (Eds.), Advances in child abuse prevention knowledge: The perspective of new leadership (pp. 43-65). Geneva: Springer International.

Fang, X., Brown, D. S., Florence, C. S., \& Mercy, J. A. (2012). The economic burden of child maltreatment in the United States and 
implications for prevention. Child Abuse and Neglect, 36(2), $156-165$.

Federal Interagency Forum on Child and Family Statistics. (2016). America's children in brief: Key national indicators of wellbeing, 2016. Retrieved from http://www.childstats.gov/americaschildren/index.asp.

Finkelhor, D., Saito, K., \& Jones, L. (2015). Updated trends in child maltreatment, 2013. University of New Hampshire Crimes Against Children Research Center. Retrieved from http://www. unh.edu/ccrc/pdf/_Updated\%20trends\%202013_dc-df-ks-df.pdf.

Geiger, J. M., Hayes Piel, M., \& Julien-Chinn, F. J. (2016). Improving relationships in child welfare practice: Perspectives of foster care providers. Child and Adolescent Social Work Journal. doi:10.1007/s10560-016-0471-3.

Geiger, J., Schelbe, L., Hayes, M., Kawam, E., Katz, C., \& Klika, J. B. (2015). Intergenerational transmission of maltreatment: Ending a family tradition. In D. Daro, A. Cohn Donnelly, L. A. Huang \& B. Powell (Eds.), Advances in child abuse prevention knowledge: The Perspective of new leadership (pp. 67-91). Geneva: Springer International.

Hammond, W. R. (2003). Public health and child maltreatment prevention: The role of the Centers for Disease Control and Prevention. Child Maltreatment, 8(2), 81-83.

Institute of Medicine and National Research Council. (2014). New directions in child abuse and neglect research. Washington, DC: National Academies Press. Retrieved from https://www.nap.edu/catalog/18331/ new-directions-in-child-abuse-and-neglect-research.

Katz, C. C., Courtney, M. E., \& Novotny, E. (2016). Pre-foster care maltreatment class as a predictor of maltreatment in foster care. Child and Adolescent Social Work Journal. doi:10.1007/ s10560-016-0476-y.

Klevens, J., Barnett, S. B. L., Florence, C., \& Moore, D. (2015). Exploring policies for the reduction of child physical abuse and neglect. Child Abuse and Neglect, 40, 1-11.

Klevens, J., Luo, F., Xu, L., Peterson, C., \& Latzman, N. E. (2016). Paid family leave's effect on hospital admissions for pediatric abusive head trauma. Injury Prevention. Advance online publication. doi:10.1136/injuryprev-2015-041702.

Lanier, P., Kohl, P. L., Raghavan, R., \& Auslander, W. (2015a). A preliminary examination of child well-being of physically abused and neglected children compared to a normative pediatric population. Child Maltreatment, 20(1), 72-79.

Lanier, P., Maguire-Jack, K., \& Welch, H. (2015b). A nationally representative study of early childhood home visiting service use in the United States. Maternal and Child Health Journal, 19(10), 2147-2158.

National Academies of Sciences, Engineering, and Medicine. (2016). Parenting matters: Supporting parents of children ages $0-8$. Washington, DC: National Academies Press. doi: $10.17226 / 21868$.

Powell, B., Bosk, E., Wilen, J., Danko, C., Van Scoyoc, A., \& Banman, A. (2015). Evidence-based programs in "real world" settings: Finding the best fit. In D. Daro, A. Cohn Donnelly, L. A. Huang \& B. Powell (Eds.), Advances in child abuse prevention knowledge: The perspective of new leadership (pp. 145-177). Geneva: Springer International.

Raghavan, R., \& Alexandrova, A. (2015). Toward a theory of child well-being. Social Indicators Research, 121(3), 887-902.

Raissian, K. M., \& Bullinger, L. R. (2016). Money matters: Does the minimum wage affect child maltreatment rates? Children and Youth Services Review. Advance online publication. doi:10.1016/j.childyouth.2016.09.033.

Schelbe, L., \& Geiger, J. M. (2016). Parenting under pressure: Experiences of parenting while aging out of foster care. Child and Adolescent Social Work Journal. doi:10.1007/s10560-016-0472-2.

US Engineering and Department of Health, Administration for Children and Families, Administration on Children, Youth and Families, Children's Bureau. (2016). Child maltreatment 2014. Available from http://www.acf.hhs.gov/programs/cb/ research-data-technology/statistics-research/child-maltreatment.

Van Scoyoc, A., Harrison, J. A., \& Fisher, P. (2016). Beliefs and behaviors of pregnant women with addictions awaiting treatment initiation. Child and Adolescent Social Work Journal. doi:10.1007/s10560-016-0474-0.

Van Scoyoc, A., Wilen, J., Daderko, K., \& Miyamoto, S. (2015). Multiple aspects of maltreatment: Moving toward a holistic framework. In D. Daro, A. Cohn Donnelly, L. A. Huang \& B. Powell (Eds.), Advances in child abuse prevention knowledge: The perspective of new leadership (pp. 21-41). Geneva: Springer International.

Wildeman, C., Emanuel, N., Leventhal, J. M., Putnam-Hornstein, E., Waldfogel, J., \& Lee, H. (2014). The prevalence of confirmed maltreatment among US children, 2004 to 2011. JAMA Pediatrics, 168(8), 706-713.

Wicked Problems Institutes. (2014). Child welfare: Wicked problems, grand challenges, \& evidence-based solutions. Retrieved from the University of North Carolina School of Social Work website: http://wickedproblems.web.unc.edu/files/2014/03/Wicked_Problems_Briefing_Sheet_Mar_2014.pdf. 